\title{
In situ monitoring of mechanosynthesis of the
}

archetypal metal-organic framework HKUST-1: the effect of liquid additives on milling reactivity

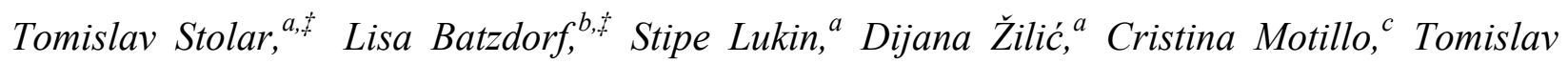
Friščić, ${ }^{c, a}$ Franziska Emmerling, ${ }^{b} *$ Ivan Halasz, ${ }^{a}{ }_{*}$ Krunoslav Užarevic ${ }^{a *}$

a) Ruđer Bošković Institute, Bijenička c. 54, 10000 Zagreb, Croatia

b) Bundesanstalt für Materialforschung und -prüfung, Richard-Willstätter-Straße 11, 12489 Berlin, Germany

c) Department of Chemistry, McGill University, 801 Sherbrooke St. West, H3A 0B8, Montreal, QC, Canada

ABSTRACT. We have applied in situ monitoring of mechanochemical reactions by high-energy synchrotron powder X-ray diffraction (PXRD) to study the role of liquid additives on the mechanochemical synthesis of the archetypal metal-organic framework HKUST-1, which was one of the first and is still among the most widely investigated metal-organic framework materials to be synthesized by solvent-free procedures. It is shown here how the kinetics and 
mechanisms of the mechanochemical synthesis of HKUST-1 can be influenced by milling conditions and additives, yielding on occasion two new and previously undetected intermediate phases containing a mononuclear copper core, and which finally rearrange to form the HKUST-1 architecture. Based on in situ data, we were able to tune and direct the milling reactions towards the formation of these intermediates, which were isolated and characterized by spectroscopic and structural means, and their magnetic properties compared to those of HKUST-1. The results have shown that despite the relatively large breadth of analysis available for such widely investigated materials as HKUST-1, in situ monitoring of milling reactions can help in detection and isolation of new materials and to establish efficient reaction conditions for mechanochemical synthesis of porous metal-organic frameworks.

\section{INTRODUCTION}

Mechanochemistry, and in particular chemical transformations by ball milling or grinding, has emerged as a versatile synthetic approach to a wide range of molecules and materials, ${ }^{1}$ from pharmaceutical cocrystals ${ }^{2}$ and organic compounds, ${ }^{3}$ to nanomaterials, ${ }^{4}$ organometallic catalysts $^{3 \mathrm{a}, 5}$ and coordination compounds. ${ }^{6}$ Besides minimizing the use of bulk solvents, mechanochemistry may provide unexpected advantages over solution chemistry, as evidenced by superior reaction selectivity ${ }^{7}$ and the ability to prepare molecules and materials that are not readily, or not at all, accessible from conventional solution-based methods. ${ }^{8}$ Mechanochemical methods have also proven suitable for the rapid and clean synthesis of microporous metalorganic framework $(\mathrm{MOF})^{9}$ or covalent organic framework materials..$^{10}$ Following the synthesis of the moderately porous copper(II) isonicotinate MOF in pioneering work by the James group, ${ }^{11}$ milling procedures have been developed for the synthesis of several popular MOF materials, ${ }^{12}$ 
including those with complex metal clusters as nodes, such as MOF-5, ${ }^{13}$ MIL-100, ${ }^{14}$ MOF-74 ${ }^{15}$ and UiO-66. ${ }^{16}$ Mechanochemically prepared materials were often found to exhibit porosity or catalytic properties that match or even surpass the analogous materials prepared from solution, with mechanochemistry offering additional synthetic benefits in energy consumption, reaction time and atom efficiency. Moreover, mechanochemical procedures enable the use of inexpensive, simple oxides or carbonates as metal precursors ${ }^{12 c}, 17$ significantly reducing the generation of waste compared to conventional solution-based approaches which use soluble metal nitrates, chlorides or acetates. While the copper(II) trimesate framework HKUST-1 ${ }^{18}$ was at first synthesized by neat grinding, ${ }^{12 a}$ it was soon thereafter shown that milling in the presence of a small amount of a liquid (i.e. liquid-assisted grinding or LAG) ${ }^{19}$ leads to HKUST-1 material with improved crystallinity and surface area. ${ }^{17 \mathrm{a}, 20}$ It has been observed on several occasions that the selectivity and enhanced reactivity in milling can be achieved by using sub-stoichiometric amounts of liquid additives (LAG), or liquids together with catalytic salts (ion- and liquidassisted grinding, ILAG). ${ }^{17 \mathrm{c}}$ While these additives were found to have a profound effect on mechanochemical reactivity, ${ }^{1 \mathrm{a}}$ the mechanisms by which they accelerate or direct milling reactions are still poorly understood. Examples where the properties of a particular LAG additive were correlated with its observed effect have only recently been described, ${ }^{21}$ while in general, it is still unpredictable which properties are important to result in a specific effect. Consequently, the use of liquid additives is still mainly based on trial-and-error.

Here, we have focused on systematically monitoring the influence of different liquid additives on the mechanochemical formation of the archetypal metal-organic framework HKUST-1. ${ }^{17 a}$ Since its discovery, ${ }^{18}$ HKUST-1 has been the subject of numerous studies due to its high stability and porosity, while its potential of having open metal sites makes it viable for separation ${ }^{22}$ and 
catalysis. $^{23}$ Due to its potential applications, HKUST-1 is one of only a few MOFs that are now commercially available. ${ }^{24}$ In order to gain direct insight into the mechanisms governing the mechanochemical formation of HKUST-1, we employed the recently developed in situ powder X-ray diffraction (PXRD) methodology to monitor ${ }^{25}$ the reaction as influenced by a choice of precursor and a range of liquid additives which differ in polarity and proton donating properties as well as their coordination capability. We have now been able to observe different reaction rates, changes in reaction pathways and diverse final yields when using different liquid additives (Figure 1). Furthermore, real-time in situ monitoring enabled us to discover two new intermediate phases, whose formation was dependent on the additives used as well as the experimental setup, and was used for tuning the milling conditions to isolate and characterize both intermediate phases. They both have monomeric copper(II) cores, and show different magnetic behavior compared to both precursors and the HKUST-1 product. The mechanosynthesis of HKUST-1 was here investigated from the most common precursor, copper(II) acetate monohydrate; $\mathrm{Cu}(\mathrm{OAc})_{2} \mathrm{H}_{2} \mathrm{O}$, but we have also used copper(II) hydroxide as a "green" precursor ${ }^{17 a}$ without the paddlewheel secondary-building unit (SBU).

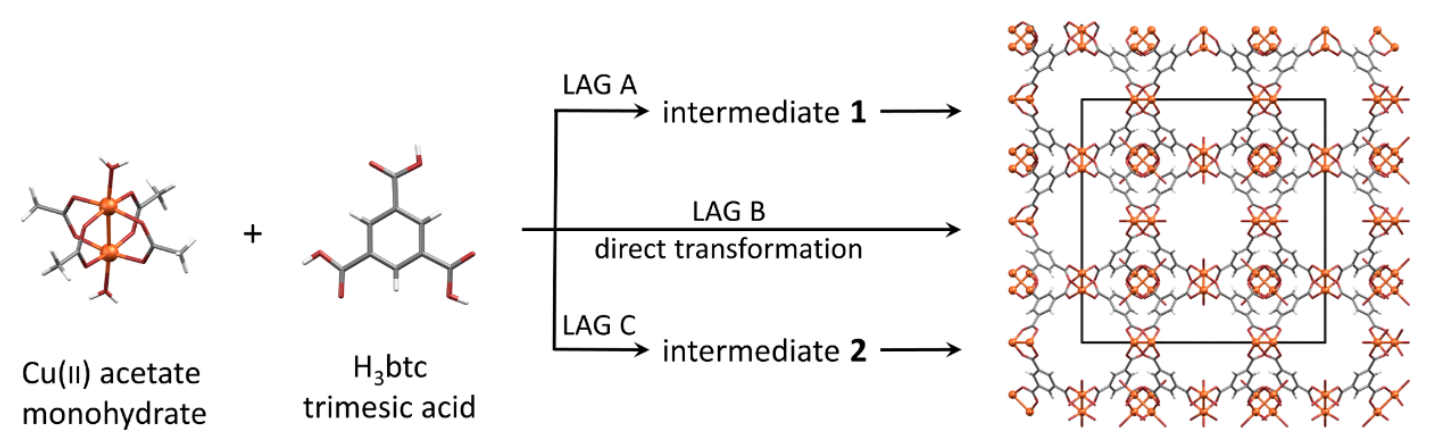

HKUST-1 
Figure 1. Mechanochemical synthesis of HKUST-1 from copper(II) acetate monohydrate precursor showing three reaction pathways which depended on the additive and reaction conditions. LAG A represents milling with additives containing longer aliphatic chains (Table 1); LAG B corresponds to milling with additives as DMSO, methanol, acetone, 2-propanol and acetonitrile; and LAG C corresponds to milling interrupted in preassigned intervals, accompanied with opening of the jar for sampling.

\section{Experimental}

Mechanochemical routines. As LAG additives we used liquids with different polarity and proticity (Table 1). The ratio of liquid volume to the weight of the reactants was kept constant for all experiments. When using copper(II) acetate monohydrate as the copper source, the overall weight of copper(II) acetate monohydrate and 1,3,5-benzenetricarboxylic acid $\left(\mathrm{H}_{3} \mathrm{btc}\right)$ was $0.25 \mathrm{~g}$ (0.72 mmol of $\mathrm{Cu}(\mathrm{OAc})_{2} \mathrm{H}_{2} \mathrm{O}$ and $\left.0.48 \mathrm{mmol} \mathrm{H}_{3} \mathrm{btc}\right)$. In another series of experiments, the overall weight of reactants were scaled up to $1000 \mathrm{mg}$ and the reaction setup was modified slightly. In all experiments the ratio of liquid volume to weight of solid reactants, the so called $\eta$ parameter, ${ }^{26}$ was maintained at a value of $0.24 \mu \mathrm{L} / \mathrm{mg}(60 \mu \mathrm{L}$ for small scale $(0.25 \mathrm{~g})$ experiments and $240 \mu \mathrm{L}$ for $1 \mathrm{~g}$ experiments).

In situ mechanochemical reaction monitoring was performed at two synchrotron sources, the European Synchrotron Radiation Facility (ESRF) in Grenoble and at the Berliner Elektronenspeicherring BESSY II, Helmholtz-Zentrum Berlin. The in situ monitoring of milling experiments at ESRF was performed at the beamline ID5B using the experimental setup described previously ${ }^{25,27}$ and an in-house modified Retsch MM301 mill operating at $30 \mathrm{~Hz}$. The reaction vessels were made from polymethymetacrylate (PMMA) with two stainless steel balls of $7 \mathrm{~mm}$ in diameter (weight $\approx 1.4 \mathrm{~g}$ per ball) as grinding media. For each experiment, the total 
weight of reactants was maintained constant, while the choice of liquid additive and $\eta^{26}$ were systematically varied.

Scaled-up milling experiments were also monitored by in situ PXRD at the $\mu$ Spot beamline of BESSY II, Berlin. The scattered intensities were collected using a two dimensional MarMosaic CCD detector $(3072 \times 3072$ pixels $) .{ }^{28}$ Due to the larger load of reactants $(1.0 \mathrm{~g}$ of solids with 240 $\mu \mathrm{L}$ of the liquid) we needed to alternate the reaction conditions slightly. We used here a $10 \mathrm{~mL}$ self-constructed PMMA vessel with two $10 \mathrm{~mm}$ stainless steel balls $(\approx 4 \mathrm{~g})$. Experiments were conducted for 30 to $90 \mathrm{~min}$ at $30 \mathrm{~Hz}$ using a vibrational ball mill (Pulverisette 23 , Fritsch GmbH, Germany). Measurements were carried out every 30 s (plus 3-4 s readout time).

Analysis of in situ PXRD monitoring. HKUST-1 is an open framework whose pores may be populated with a variety of guest species, including the reactants themselves, whose distribution does not necessary adhere to the structure symmetry, thereby hindering Rietveld refinement. Analysis of the in situ PXRD reaction monitoring data was achieved by scaling the intensities of a set of reflections belonging to HKUST-1. This set of HKUST-1 reflections was initially obtained by a Pawley ${ }^{29}$ refinement of the last diffraction pattern from the LAG(MeOH) reaction in which this framework was the only remaining crystalline phase in the reaction mixture. For the analysis of other data sets, this set of reflections was, for each diffraction pattern individually, multiplied by a refined scale factor. Thus refined scale factor of each dataset was taken as a direct indication of the reaction progress towards the formation of HKUST-1. Scaling of the HKUST-1 intensities in different experiments relative to the same initial set of intensities allows comparison of reaction rates and yields of different LAG and NG experiments relative to the product of the LAG(MeOH) reaction.. In addition to the scale factor for HKUST-1 intensities, each diffraction pattern was modeled by refining unit cell and background parameters as well as 
peak shape parameters. Diffraction patterns were processed in an automated fashion using the program Topas $^{30}$ in batch mode. Refined parameters were written into a text file and used for further analysis and plotting. The relative scale factor, used as an indicator of reaction progress, shows large variations arising from variations in the amount of the material in the X-ray beam for each particular diffraction pattern collected during in situ monitoring. Time-resolved 2dimensional X-ray diffractograms were prepared using Mathematica ${ }^{31}$ after subtracting the background of each diffraction pattern by the Sonneveld-Visser ${ }^{32}$ algorithm implemented in Powder3D. ${ }^{33}$

Ex situ milling experiments were performed by using the same selection of milling vessels and balls as for the corresponding in situ monitoring experiments, in a Retsch MM301 shaker ball mill operating at $30 \mathrm{~Hz}$. Samples prepared in laboratory were analyzed by powder X-ray diffraction (PXRD) using the Phillips PW 3710 diffractometer with $\mathrm{CuK \alpha}$ radiation, operating at a tension of $40 \mathrm{kV}$ and current of $40 \mathrm{~mA}$. The data was collected using a flat plate sample on a zero background in Bragg-Brentano geometry, between $4^{\circ}$ and $40^{\circ}(2 \theta)$ with a step size of $0.02^{\circ}$ and $1.0 \mathrm{~s}$ counting per step.

Experiments on a 1 gram scale were conducted using a vibrational ball mill (Pulverisette 23, Fritsch $\mathrm{GmbH}$, Germany) with a $10 \mathrm{~mL}$ stainless steel reaction vessel and a total solid loading of $1000 \mathrm{mg}$ (with $240 \mu \mathrm{L}$ liquid). To achieve efficient mixing, milling experiments were performed at $30 \mathrm{~Hz}$ using two stainless steel balls (each ball weighed $4 \mathrm{~g}$ ). Sampling was typically conducted every $0 \mathrm{~s}, 10 \mathrm{~s}, 60 \mathrm{~s}, 5 \mathrm{~min}, 15 \mathrm{~min}$, and $60 \mathrm{~min}$ to perform qualitative analysis of the reaction pathway. Alternatively, ex situ experiments were conducted with additives ethanol and 1-butanol, where the sampling was performed for every $1 \mathrm{~min}$ until 5 min of reaction time; for every 5 min until $60 \mathrm{~min}$ of reaction time, and for every 10 min until 120 min of milling. For 
each sampling, the mill was stopped and the sample was taken from the reaction vessel and analyzed by PXRD. Powder diffraction measurements were performed on a diffractometer D8 Discover (Bruker AXS, Karlsruhe, Germany; Lynxeye detector) operated in transmission geometry $\left(\mathrm{Cu}-\mathrm{K} \alpha_{1}\right.$ radiation, $\left.\lambda=0.154056 \mathrm{~nm}\right)$. Samples were sealed in glass capillaries $(0.5$ mm; WJM-Glas, Müller GmbG, Berlin, Germany). Measurements were performed at room temperature in a $2 \theta$ range from $5-50^{\circ}$, step size of 0.009 and $0.1-0.2 \mathrm{~s}$ per step.

Intermediate phase isolation. Milling experiments were performed by altering reaction times, copper precursor, molar ratio of the reactants, type of liquid additive, and the amount of the liquid additive. The best results were obtained from $\mathrm{Cu}(\mathrm{II}): \mathrm{H}_{3} \mathrm{btc}=1: 2$ molar ration with ethanol or 1-butanol as liquid additives.

Structure solution. The structure solution of intermediate 2 was derived from PXRD data. The PXRD data were indexed using the indexing routine of the software TOPAS (Version 5, Bruker AXS, 2014) Simulated annealing was conducted in EXPO.$^{34}$ Final Rietveld refinements was performed using TOPAS. The experimental details, Rietveld plot and difference plots are shown in Supplementary information, Figure S25.

Electron spin resonance (ESR) spectroscopy was conducted on microcrystalline samples of the mechanochemically prepared materials using an X-band Bruker Elexsys $580 \mathrm{FT} / \mathrm{CW}$ spectrometer equipped with a standard Oxford Instruments model DTC2 temperature controller. The measurements were performed at a microwave frequency of around $9.7 \mathrm{GHz}$ with the magnetic field modulation amplitude of $0.5 \mathrm{mT}$ at modulation frequency of $100 \mathrm{kHz}$. The ESR spectra were recorded from liquid nitrogen up to room temperature (78 K and $297 \mathrm{~K}$ ). 
Fourier-transform infrared attenuated total reflectance (FTIR-ATR) measurements were conducted using a Perkin-Elmer Spectrum Two instrument with a diamond crystal Quest ATR Accessory, in the range of $450-4000 \mathrm{~cm}^{-1}$.

\section{Results and discussion}

\section{Direct synthesis of HKUST-1 by mechanochemistry}

The paddlewheel secondary building unit (SBU) in HKUST-1 characteristic for copper carboxylates is also found in copper acetate monohydrate, $\left[\mathrm{Cu}(\mathrm{OAc})_{2}\left(\mathrm{H}_{2} \mathrm{O}\right)\right]_{2}$, which is the most common precursor for either solution $^{18}$ or mechanochemical ${ }^{12 \mathrm{a},}{ }^{20 \mathrm{a}}$ synthesis of HKUST-1. Herein, in situ monitoring of the neat grinding synthesis of HKUST-1 starting from copper(II) acetate monohydrate and $\mathrm{H}_{3}$ btc performed in PMMA vessels revealed a very slow low-yielding reaction, and a large amount of copper acetate remaining after 50 min milling (Figure $2 \mathrm{a}$ ). As the use of LAG procedures was generally found to be beneficial for encouraging reactivity during the synthesis of metal-organic open architectures, ${ }^{25}$ we conducted a systematic screen of different liquid additives aimed at determining how the mechanosynthesis of HKUST-1 could be accelerated by LAG. It was shown immediately that the weakly-coordinating liquid additives such as hexane, cyclohexane, toluene, chloroform, dichloromethane, and even polar nitromethane, led to little or no enhancement compared to neat grinding (Figures 2, S1-S5). Even though these liquids could have entered the pores of the nascent HKUST-1 and stabilized it, they had little effect on the formation of HKUST-1 (Figure 2b). 


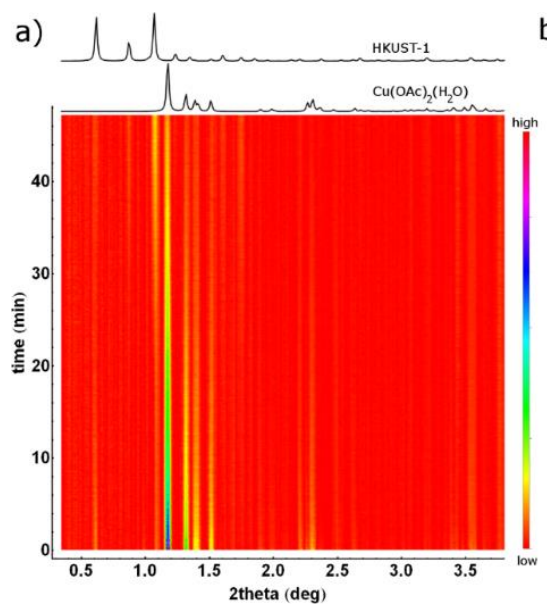

b)

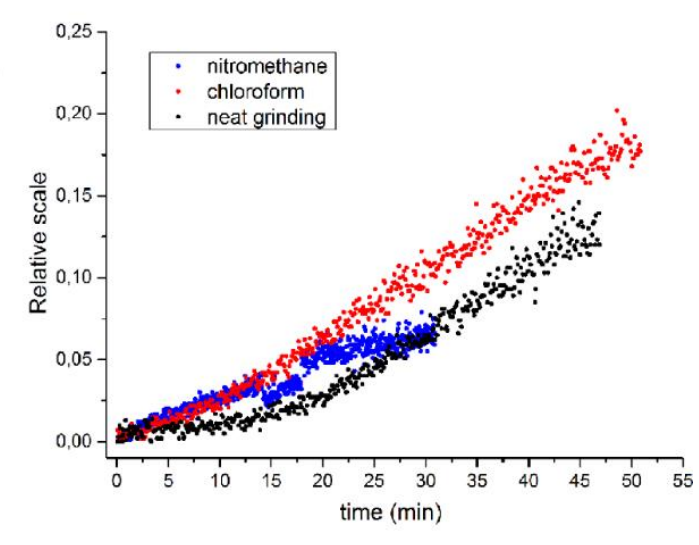

Figure 2. (a) In situ monitoring of the mechanochemical formation of HKUST-1 from copper(II) acetate hydrate and $\mathrm{H}_{3}$ btc under neat milling conditions. Calculated diffraction patterns of participating crystalline phases are given on top of the time-resolved diffractogram. (b) Comparison of the formation efficiency of HKUST-1 under LAG reaction conditions using nitromethane and chloroform to neat grinding. Relative scaling of HKUST-1 intensities is explained in the Experimental section.

In contrast, the formation of HKUST-1 by LAG was greatly facilitated in the presence of protic liquid additives. Alcohols, as polar and protic liquids, were the most efficient at accelerating the formation of HKUST-1, with methanol providing the fastest reactions and the highest reaction yield. With methanol as the additive, HKUST-1 was observed almost immediately in the reaction mixture, and maximum conversion was reached after ca. 5 minutes milling (Fig. 3a). Slower conversions were observed when using the same volumes of ethanol or iso-propanol as additives, requiring ca. 20 min for reaction completion (Fig. 3b). Polar aprotic liquid additives such as acetonitrile, acetone, $N, N$-dimethylformamide (DMF), $N, N$ diethylformamide (DEF), were less efficient than polar and protic liquids at facilitating HKUST- 
1 formation. Moreover, acetonitrile provided the fastest initial reaction in our set of experiments but a poor final yield (Figure 3c), which may have been due to the competition between the additive (acetonitrile) and $\mathrm{H}_{3}$ btc for the copper cations, thus hindering the formation of HKUST1. LAG using acetone, a mildly acidic O-donor liquid, was initially slower when compared to LAG using acetonitrile but the final yield was around three times higher. The ability of DMF and DEF, basic O-donor liquids, to accelerate the reaction was similar to acetone in terms of HKUST-1 formation, providing slower reactions but better final yield than for LAG using acetonitrile. To establish whether N-donor liquids could interfere with the HKUST-1 synthesis, we performed the in situ monitoring of the reaction in the presence of pyridine, a liquid additive known for its affinity towards coordination to copper. Milling with pyridine as liquid additive resulted in exclusive formation of a known copper(II) 2-D coordination polymer with the formula $\left[\mathrm{Cu}_{3}(\mathrm{btc})_{2}(\mathrm{py})_{3}\right]_{\mathrm{n}}(\mathrm{Cambridge}$ Structural Database code HUDHET), while the diffraction signals related to HKUST-1 could not be detected (Figure S22). These results suggest that the coordinating capabilities of the liquid additive have a profound effect on mechanochemical formation of HKUST-1.

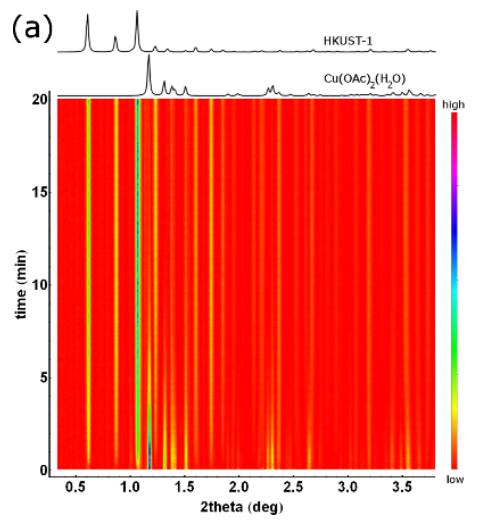

(b)

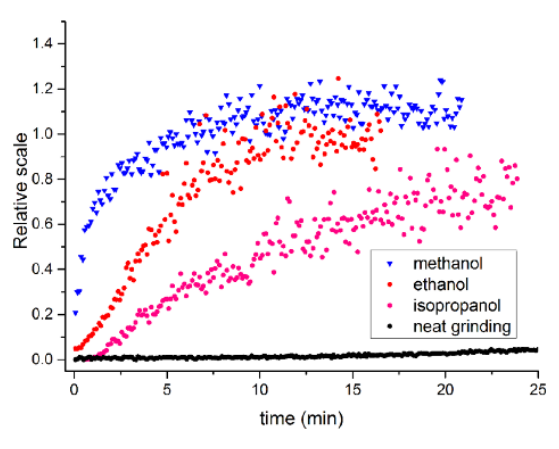

(c)

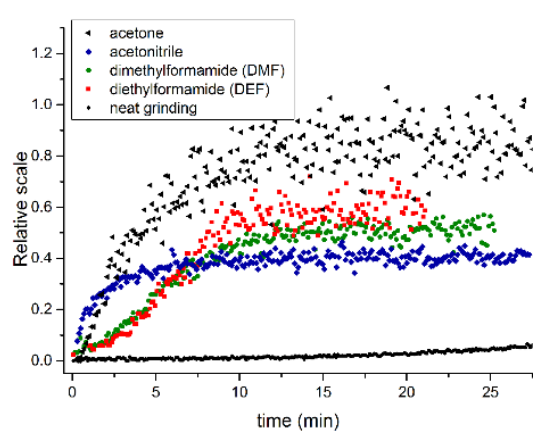

Figure 3. In situ monitoring of the formation of HKUST-1 using (a) methanol as an additive; (b) formation of HKUST-1 under LAG reaction conditions using simple alcohols in comparison to 
neat grinding: and (c) formation of HKUST-1 under LAG reaction conditions using various aprotic liquids in comparison to neat grinding. Relative scaling of HKUST-1 intensities is explained in the Experimental section. Scattering of the values for the scale factor is due to variable amount of the sample in the X-ray beam for the collection of consecutive diffraction patterns. This scattering is most pronounced for acetone where the amount of HKUST-1 is highest causing the strongest absolute variations of HKUST-1 in the beam while relative variations are similar in all experiments.

While the above results suggest that the selection of LAG liquid can accelerate or direct the mechanochemical synthesis of HKUST-1, the volume of LAG additive was found to have a profound effect on HKUST-1 formation. Adding $20 \mu \mathrm{L}$ of methanol instead of previously used $60 \mu \mathrm{L}$ resulted in the slower and less extensive formation of HKUST-1 (Figure 4a). Mixing the protic additive with an aprotic one, such as in experiments involving ethanol-chloroform mixtures revealed that the reaction rate is strongly dependent only on the amount of the protic liquid. For example, the reaction profiles were almost identical when using only $20 \mu \mathrm{L}$ of ethanol as the LAG additive, or ethanol $(20 \mu \mathrm{L})$ together with chloroform $(40 \mu \mathrm{L})$. Furthermore, increasing the ethanol content in the liquid mixture led to higher conversions and reaction rates (Figure 4b). 

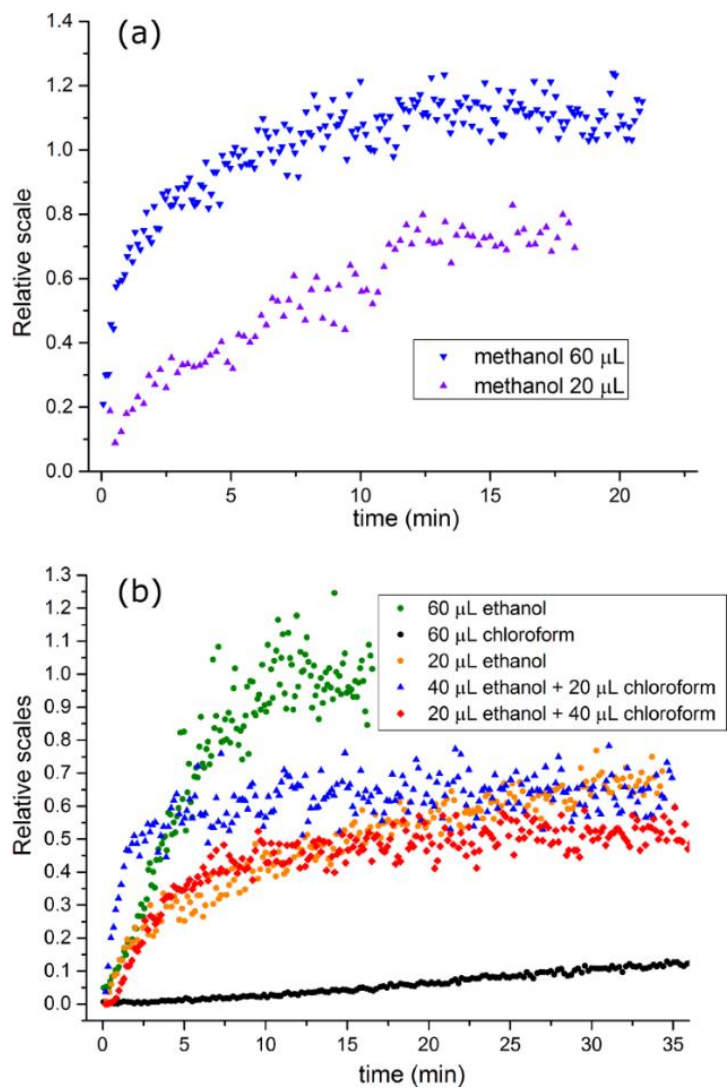

Figure 4. The amount of the protic liquid additive affects the reaction yield. (a) With lower amount of the methanol liquid additive, the yield is correspondingly lower, and (b) mixing the protic additive with aprotic liquid will have almost no effect on the reaction rate and yield. Relative scale of HKUST-1 intensities is explained in the Experimental section.

\section{Intermediates in mechanosynthesis of HKUST-1}

Our studies also reveal that the LAG additives can have an important role in governing the reaction pathway for the mechanochemical formation of HKUST-1. Analysis of the mechanochemical reactions forming of HKUST-1 from copper(II) acetate monohydrate revealed 
the intended product as the only crystalline phase formed when all LAG additives other than ethanol and DMF were used. With these latter additives, an intermediate phase (1) was observed, as evidenced by the appearance of a strong characteristic low-angle X-ray reflection $(d=14.7 \AA$; $2 \theta=6.1^{\circ}$ for $\mathrm{CuK} \alpha_{1}$ ). While 1 was present, a significant amount of unreacted copper(II) acetate monohydrate was still evident in the reaction mixture (Figures 5a, S18), along with the partially formed HKUST-1 product. At the same time the diffraction signals of $\mathrm{H}_{3}$ btc were no longer visible after around 5 min milling. Phase $\mathbf{1}$ appears in the reaction mixture immediately after the milling is initiated and disappears after ca. 12 minutes, along with the remaining copper(II) acetate monohydrate, to yield HKUST-1 as the only crystalline phase. However, formation of 1 is not related exclusively to ethanol and DMF. Repeated LAG experiments with longer-chain alcohols, and THF or ethyl acetate as additives (Table 1) revealed the same stepwise reaction pathway which resulted with HKUST-1 as the only product. 

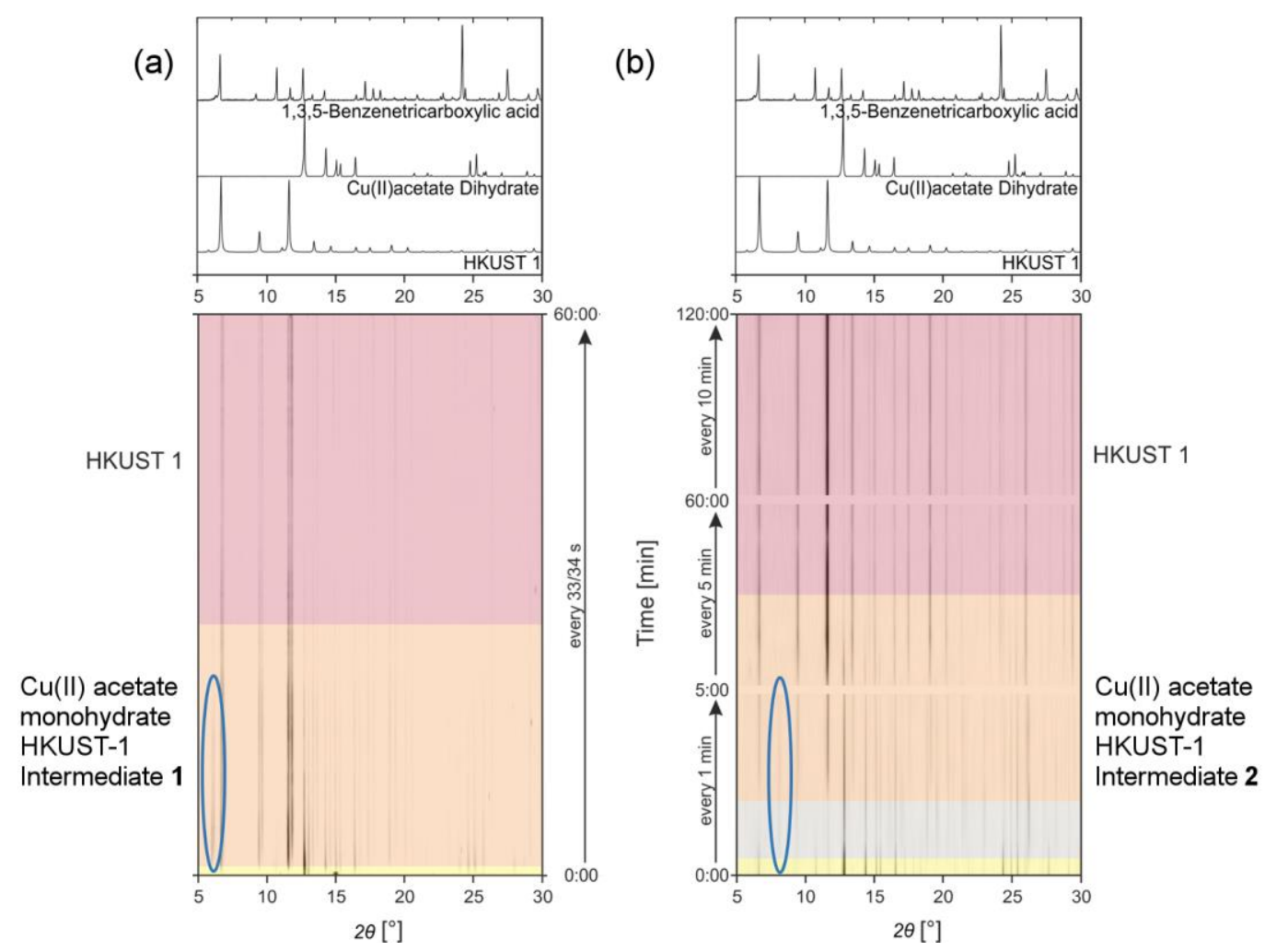

Figure 5. (a) In situ monitoring of the reaction between copper(II) acetate hydrate and $\mathrm{H}_{3}$ btc (3:2 molar ratio) with ethanol as liquid where the intermediate $\mathbf{1}$ is visible in the first 15 min milling and b) same mechanochemical reaction followed by stepwise ex situ analyses by stopping the mill and sampling.

Table 1. Effect of milling in the LAG processes on the occurrence of the intermediate phases and the product of milling. In typical experiment, $250 \mathrm{mg}$ of reactants in total would be milled with $60 \mu \mathrm{L}$ of liquid. In all experiments (except experiments with 1-butanol, 1-hexanol and benzonitrile), opening of the jar for sampling would lead to formation of intermediate 2 and finally to formation of HKUST-1.

\begin{tabular}{|l|l|l|l|l|l|}
\hline Liquid & Protic & Permeability & Monitoring & Intermediate & Product \\
\hline Hexane & & 1.88 & in situ & - & $-^{*}$ \\
\hline
\end{tabular}




\begin{tabular}{|c|c|c|c|c|c|}
\hline Cyclohexane & & 2.02 & in situ & - & $-*$ \\
\hline Toluene & & 2.38 & in situ & - & $-*$ \\
\hline Chloroform & & 4.81 & in situ & - & $-*$ \\
\hline Dichloromethane & & 6.00 & in situ & - & $-^{*}$ \\
\hline DMSO & & 46.7 & in situ & - & HKUST-1 \\
\hline Acetonitril & & 37.5 & in situ & - & HKUST-1 \\
\hline Methanol & + & 35.2 & in situ & - & HKUST-1 \\
\hline Acetone & & 20.7 & in situ & - & HKUST-1 \\
\hline 2-propanol & + & 19.92 & in situ & - & HKUST-1 \\
\hline 2-butanone & & 18.59 & in situ & - & HKUST-1 \\
\hline Ethanol & + & 24.8 & in situ & 1 & HKUST-1 \\
\hline 1-propanol & + & 20.33 & in situ & 1 & HKUST-1 \\
\hline 1-butanol & + & 17.51 & in situ & 1 & HKUST-1 \\
\hline 1-hexanol & + & 13.30 & in situ & 1 & HKUST-1 \\
\hline Tetrahydrofuran & & 7.58 & in situ & 1 & HKUST-1 \\
\hline Ethyl acetate & & 6.00 & in situ & 1 & HKUST-1 \\
\hline Diethylformamide & & 29.02 & in situ & 1 & HKUST-1 \\
\hline Benzonitrile & & 25.2 & in situ & 1 & HKUST-1 \\
\hline
\end{tabular}

* Although HKUST-1 is not a product of milling procedure, it forms upon aging of the milled reaction mixture in the air.

In order to isolate and characterize 1, we conducted a series of experiments in which the milling was stopped at predetermined periods, allowing samples to be taken and analyzed by ex situ PXRD. Surprisingly, another intermediate phase (2), different from 1, was observed (Figures $5 \mathrm{~b}, \mathrm{~S} 20)$. Analysis of the PXRD pattern of the reaction mixture revealed the formation of compound 2 along with copper(II) acetate monohydrate and HKUST-1, while the reflections of $\mathrm{H}_{3}$ btc were no longer observable after 3 minutes milling (Figure 5b). This suggested that a lower 
ratio of $\mathrm{Cu}$ (II) to $\mathrm{H}_{3}$ btc might be beneficial for the isolation of $\mathbf{2}$. Indeed, the intermediate $\mathbf{2}$ was isolated in pure form after milling copper(II) acetate and $\mathrm{H}_{3}$ btc in the 1:2 stoichiometric ratio for 5 minutes. The crystal structure of $\mathbf{2}$ was solved from powder X-ray diffraction data, revealing that the compound crystallizes in the monoclinic $P 2{ }_{1} / c$ space group (Table S1). The structure solution revealed a coordination compound with two $\mathrm{H}_{2} \mathrm{btc}^{-}$anions and two water molecules coordinated to a single $\mathrm{Cu}(\mathrm{II})$ ion (Figure 6). The crystal structure exhibits extensive hydrogen bonding between the carboxylic acid functionalities of the anionic ligand and water, giving rise to a complex supramolecular network. While the central $\mathrm{Cu}$ (II) cation is coordinated with four ligands arranged in a square-planar fashion, two oxygen atoms belonging to water molecules from the neighboring complexes are only $\approx 2.86 \AA$ away, extending the coordination sphere of each $\mathrm{Cu}(\mathrm{II})$ into an elongated octahedron. The nearest contact between two copper ions is with copper centers from the complexes donating apical oxygen atoms, where the $\mathrm{Cu} \cdots \mathrm{Cu}$ distance is $\approx 3.654 \AA$, with the angle $(\mathrm{O}$ (apical) $\cdots \mathrm{Cu} \cdots \mathrm{Cu})$ of $32.83^{\circ}$ (Figure S23). It seems thus that the stopping the mechanochemical reaction and opening of the jar for sampling induces dissociation of a paddlewheel SBU of the copper(II) acetate and formation of simple mononuclear intermediate which, in the right stoichiometry of reactants, reacts with the remaining metal precursor to form HKUST-1. 

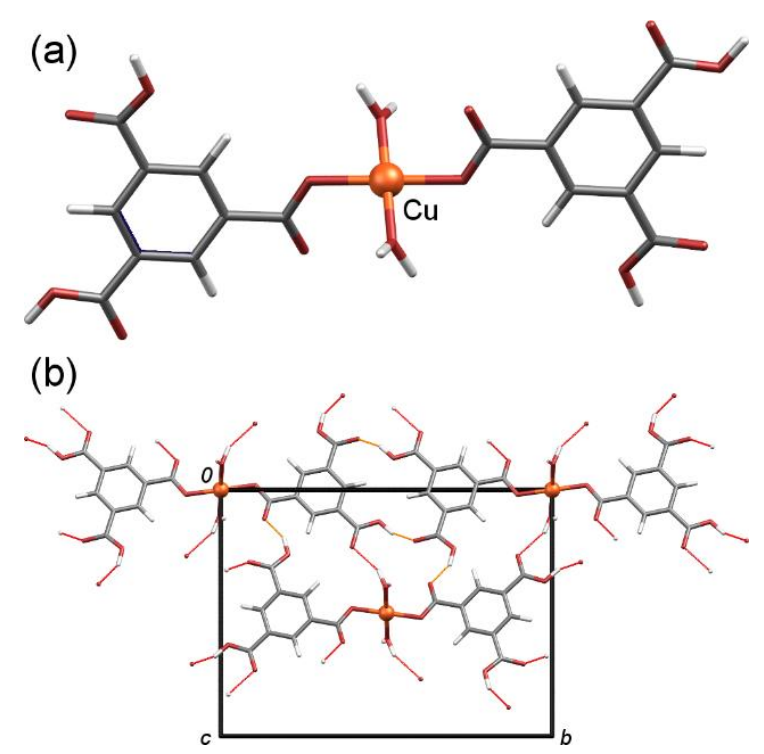

Figure 6. (a) Molecular structure of intermediate 2 and (b) hydrogen-bonded network in crystal structure of 2 as viewed down the crystallographic $a$ axis. Hydrogen bonds are represented by dotted lines.

Detection and isolation of $\mathbf{2}$ exclusively upon stepwise reaction monitoring highlights the fact that opening and closing of the milling vessel can affect the pathway of the mechanochemical reaction. It was previously shown that the opening of the reaction vessel and the interruption of the milling process can steer the reaction towards products which differ from those obtained by uninterrupted milling. ${ }^{35}$ In this case, exposing the reaction mixture to atmosphere resulted most likely in partial evaporation of liquid components used (acetic acid, water and ethanol), and at the same time cooling and relaxation of reaction mixture followed by the formation of 2 . For that reason, we revisited the LAG syntheses of HKUST-1 with non-polar and non protic liquids (hexane, cyclohexane, toluene, chloroform, dichloromethane), where the formation of HKUST-1 was extremely slow and diffraction signals of HKUST-1 could be barely visible after milling was finished. Opening of the jar for sampling resulted again in the formation of the intermediate phase 2, with the formation of HKUST-1 having been observed upon further milling (Table 1). 
In situ monitoring of reactions with methanol, acetonitrile, 2-propanol, acetone, 2-butanone and DMSO as additives showed direct formation of HKUST-1 with no observable intermediate (Table 1). However, opening of the jar for sampling and ex situ analyses also led to HKUST-1 formation via intermediate 2.

Although the opening of the jar offers a simple way for the synthesis of $\mathbf{2}$, the in situ observed phase 1 was not visible pure in any of the PXRDs collected by stepwise monitoring. In order to isolate 1, we attempted the synthesis of HKUST-1 from different copper(II) source, namely copper(II) hydroxide (which does not have the paddlewheel SBU) and $\mathrm{H}_{3}$ btc in a 3:2 molar ratio under LAG conditions using ethanol as the liquid additive so as to slow down the formation of HKUST-1, which is almost immediately visible in reactions from copper(II) acetate monohydrate. Using copper hydroxide as the metal source resulted in intermediate $\mathbf{1}$ being observed as a lasting intermediate with strong and sharp reflections, indicating its high crystallinity. It was formed quickly upon initiation of milling and its corresponding reflections persisted for almost $20 \mathrm{~min}$ before their reduction in intensity was accompanied by the appearance of those of HKUST-1 (Figure 7). 


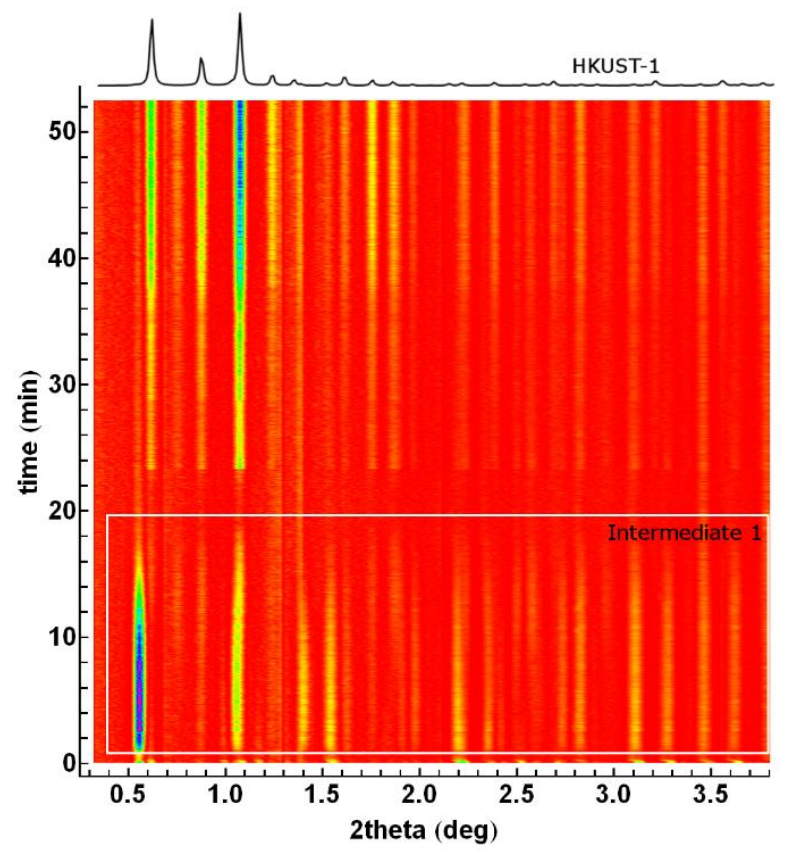

Figure 7. Time-resolved diffractogram for the LAG of copper(II) hydroxide and $\mathrm{H}_{3}$ btc (3:2 molar ratio) using ethanol as the liquid additive. Peaks belonging to intermediate $\mathbf{1}$ are enclosed in the white rectangle.

Based on these results we have switched to copper(II) hydroxide as the copper precursor and used other alcohols as LAG additives in further attempts to isolate the intermediate 1. Even though in situ monitoring did not reveal formation of 1 when using 2-propanol, stepwise analysis reveals increasingly facile formation of $\mathbf{1}$ formation when using longer-chain alcohols. By using LAG with 1-butanol and a 1:2 stoichiometric ratio of copper(II) hydroxide to $\mathrm{H}_{3}$ btc, we were able to isolate $\mathbf{1}$ as a pale-blue solid and to collect its high-resolution X-ray powder diffraction pattern. Repeating the experiments using the same reaction conditions but with other alcohols (ethanol, 1-propanol, 1-hexanol), we again obtained 1 with an identical diffraction pattern. We were however unable to determine the crystal structure of $\mathbf{1}$. The strong low-angle reflection is characteristic of layered structures and we were able to index the diffraction pattern with an orthorhombic unit cell. Diffraction pattern of intermediate $\mathbf{1}$ and the Pawley fit confirming the 
unit cell are given in Supporting information (Figure S24). Since the best results were again gained with 1:2 molar ratio and no other compounds were observable by PXRD or spectroscopic analyses, we assume the molecular composition of $\mathbf{1}$ to be similar to the composition of the intermediate 2. This was further corroborated by their FTIR-ATR spectra which are almost identical. Also, in the spectra of both $\mathbf{1}$ and $\mathbf{2}$, the characteristic peak corresponding to the $\mathrm{C}=\mathrm{O}$ stretching vibrations lie at $1703 \mathrm{~cm}^{-1}$ indicating the presence of still free carboxylic groups from the $\mathrm{H}_{3}$ btc ligand (Figure S26).

\section{Magnetic properties of mechanochemically prepared HKUST-1 and the intermediate}

\section{phases 1 and 2}

To gain insight into the local environment of the copper cation in both intermediates and to compare their magnetic properties with the properties of two used precursors and the mechanochemically prepared HKUST-1, we employed electron spin resonance (ESR) spectroscopy. ESR spectra of all investigated compounds at the lowest measured temperature (78 K) are presented in Fig. 8. The recorded spectra of two used precursors, copper(II) acetate monohydrate and $\mathrm{Cu}(\mathrm{OH})_{2}$ as well as of HKUST-1 are in agreement with the spectra found in the literature; all are well known and thoroughly characterized. In paddlewheel unit of $\left[\mathrm{Cu}(\mathrm{OAc})_{2}\left(\mathrm{H}_{2} \mathrm{O}\right)\right]_{2}$, there are two strongly antiferromagnetically coupled copper ions with spin $S$ $=1 / 2$ with ground singlet and an excited triplet state and its ESR spectra can be described by the total spin $S=1 .^{36}$ Copper(II) hydroxide is a low-dimensional antiferromagnet with Néel temperature $T_{N} \approx 20 \mathrm{~K}^{37}$ and in $\mathrm{X}$-band, it is ESR silent, from room down to liquid helium temperature. ${ }^{38}$ Here observed very weak and broad signal could be assigned to defects that occur during an aging of the sample, in agreement with similar results found in the literature. ${ }^{38-39}$ The spectrum of HKUST-1 is a superposition of two contributions; the first stronger contribution 
observed at magnetic field $\approx 330 \mathrm{mT}$ corresponds to paramagnetic copper ions with spin $S=1 / 2$ and the second weaker contribution belongs to two coupled copper ions with total spin $S=1 .^{40} \mathrm{In}$ accordance with literature, this main resonance originates from $\left[\mathrm{Cu}\left(\mathrm{OH}_{2}\right)_{6}\right]^{2+}$ complex, a defect formed during the synthesis, heterogeneously distributed over the HKUST-1 pores. The second weaker contribution, whose part of the spectrum is shown enlarged in Figure 8 below HKUST-1 spectrum, has origin in strongly antiferromagnetically coupled copper ions and due to similar paddle-wheel building block, it is similar to the spectrum of copper(II) acetate hydrate. Beside this $S=1$ dimer signal, there is also another contribution from the exchange coupling between dimers. ${ }^{40 a, 41}$

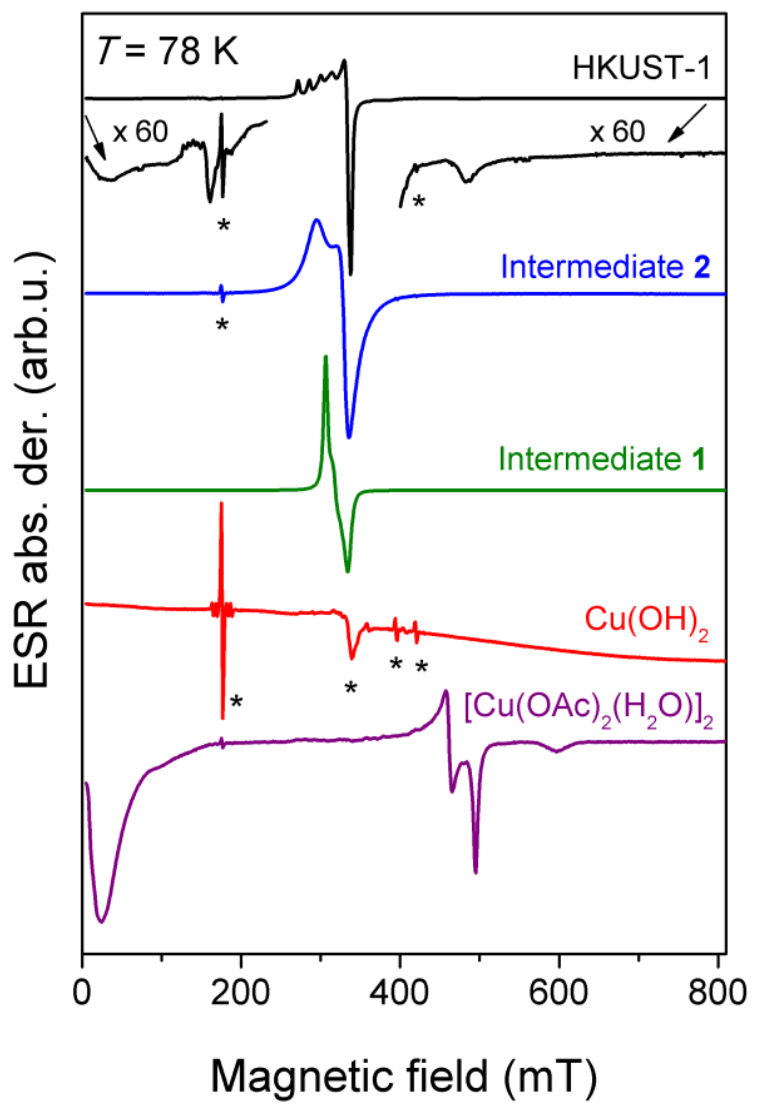


Figure 8. ESR spectra of the investigated compounds at $T=78 \mathrm{~K}$. The signals marked with asterisks originate from the ESR cavity.

Contrary to the magnetically coupled copper(II) ions in the both precursors and HKUST-1 product, ESR spectra point to the presence of the monomeric copper(II) structures in intermediate compounds. The temperature dependence of the spectra and more detailed ESR analysis of two intermediates is given in SI. From the spectral simulation, the following values of $\mathbf{g}$-tensors were obtained: $g_{\mathrm{x} 1}=2.068, g_{\mathrm{y} 1}=2.140, g_{\mathrm{z} 1}=2.258 ; g_{\mathrm{x} 2}=g_{\mathrm{y} 2}=2.075, g_{\mathrm{z} 2}=2.350$, for intermediate $\mathbf{1}$ and 2 , respectively (Figure S27). "Axial" parameters with $g_{z}>g_{y}=g_{x}$ obtained for 2 reveal the $\mathrm{d}_{\mathrm{x} 2-\mathrm{y} 2}$ orbital as the ground state of copper unpaired electron, in agreement with the crystallographic structure of $2 .^{42}$ "Rhombic" parameters with $g_{z}>g_{y}>g_{x}$ obtained for $\mathbf{1}$ point to "intermediate situation", with geometry between octahedral, square pyramidal or square planar on one side and compressed octahedral or trigonal bipyramidal on the other side. ${ }^{42}$ A comparison with crystallographic parameters are not possible due to the unknown crystal structure of $\mathbf{1}$ but the parameter $R=\left(g_{y}-g_{x}\right) /\left(g_{z}-g_{y}\right)=0.61<1$ reveals that the ground state in $\mathbf{1}$ is also predominantly $\mathrm{d}_{\mathrm{x} 2-\mathrm{y} 2 .}{ }^{42}$ The results from ESR suggest that both intermediate phases $\mathbf{1}$ and $\mathbf{2}$ are complexes with mononuclear copper(II) cores.

\section{CONCLUSION}

In situ synchrotron PXRD monitoring of the mechanochemical synthesis of HKUST-1 from copper(II) acetate hydrate revealed a lively participation of the liquid additive in the formation of HKUST-1, with three different reaction pathways determined. While some additives support the direct transformation of copper(II) acetate and $\mathrm{H}_{3}$ btc to HKUST-1, without any observable crystalline intermediate phases, using ethanol and higher alcohols was found to steer the 
HKUST-1 formation via an intermediate phase 1. In our experimental setup, dry milling and LAG using aprotic and non-polar liquids would not yield any significant amount of HKUST-1 during milling but HKUST-1 would form after aging of the milled reaction mixture in air. Furthermore, ex situ study revealed that relaxation of the reaction mixture and temperature variations through repeated stopping and starting of the milling process as well as opening of the reaction vessel induced formation of another intermediate $\mathbf{2}$, no matter of the liquid additive used. Data collected from in situ and fast ex situ monitoring helped us to tune the reaction conditions and stoichiometry of the reactants, and to isolate intermediates $\mathbf{1}$ and $\mathbf{2}$ as pure phases, allowing their spectroscopic and structural characterization. Both intermediates are mononuclear complexes, meaning that the paddlewheel SBU of copper(II) acetate dissociated in LAG with ethanol or higher alcohols, forming a compounds with a mononuclear copper core, which further reacted to form HKUST-1. Such reactivity using different liquids, or the same liquid but in different amounts, further stresses the importance of the liquid additive for the formation of HKUST-1. Clearly, the role of the liquid is not only to populate the voids in the nascent MOF, but even more so to activate the reactants and direct its mechanochemical formation. Our future work will be focused on studying in detail the specific liquid-MOF interactions responsible for MOF formation and stabilization.

\section{ASSOCIATED CONTENT}

\section{Supporting Information.}

The following files are available free of charge. 2D diagrams of in situ PXRD monitoring experiments using different liquid additives, Pawley refinement data for the intermediate 1, 
FTIR-ATR data for all reactants and products, ESR data for intermediates 1 and 2.

\section{AUTHOR INFORMATION}

\section{Corresponding Author}

Krunoslav Užarević, krunoslav.uzarevic@irb.hr

Ivan Halasz, ihalasz@irb.hr

Franziska Emmerling, franziska.emmerling@bam.de

\section{$\underline{\text { Author Contributions }}$}

The manuscript was written through contributions of all authors. All authors have given approval to the final version of the manuscript. $¥$ These authors contributed equally.

\section{Funding Sources}

SL, IH and KU are supported by Croatian Science Foundation grant UIP-2014-09-4744. IH acknowledges the financial support of the Adris foundation. DŽ acknowledges the financial support from the Croatian Science Foundation (grant 1108). TF acknowledges the financial support of the NSERC Discovery Grant and the McGill University W. J. Dawson Scholarship.

\section{ACKNOWLEDGMENT}

Mr.Vitomir Stanišić is acknowledged for help with experimental setup. We are grateful to Dr. Manda Ćurić for critically reading the manuscript. Financial support from the ESRF ID15B and the Croatian Science Foundation (Grant Nos. UIP-2014-09-4744 and 1108) is gratefully acknowledged. IH acknowledges the Adris foundation for supporting this work. SL is supported 
by the Croatian Science Foundation. TF acknowledges the financial support of the NSERC

Discovery Grant and the McGill University W. J. Dawson Scholarship.

\section{REFERENCES}

1. (a) James, S. L.; Adams, C. J.; Bolm, C.; Braga, D.; Collier, P.; Friščić, T.; Grepioni, F.; Harris, K. D. M.; Hyett, G.; Jones, W.; Krebs, A.; Mack, J.; Maini, L.; Orpen, A. G.; Parkin, I. P.; Shearouse, W. C.; Steed, J. W.; Waddell, D. C., Mechanochemistry: opportunities for new and cleaner synthesis. Chem. Soc. Rev. 2012, 41, 413-447; (b) Do, J.-L.; Friščić, T., Mechanochemistry: A Force of Synthesis. ACS Central Science 2017, 3, 13-19.

2. (a) Braga, D.; Maini, L.; Grepioni, F., Mechanochemical preparation of co-crystals. Chem. Soc. Rev. 2013, 42, 7638-7648; (b) Friščić, T., Supramolecular concepts and new techniques in mechanochemistry: cocrystals, cages, rotaxanes, open metal-organic frameworks. Chem. Soc. Rev. 2012, 41, 3493-3510; (c) Tan, D.; Loots, L.; Friščić, T., Towards medicinal mechanochemistry: evolution of milling from pharmaceutical solid form screening to the synthesis of active pharmaceutical ingredients (APIs). Chem. Commun. 2016, 52, 7760-7781. 3. (a) Hernández, J. G.; Friščić, T., Metal-catalyzed organic reactions using mechanochemistry. Tetrahedron Lett. 2015, 56, 4253-4265; (b) Wang, G.-W., Mechanochemical organic synthesis. Chem. Soc. Rev. 2013, 42, 7668-7700.

4. (a) Balaz, P.; Achimovicova, M.; Balaz, M.; Billik, P.; Cherkezova-Zheleva, Z.; Criado, J. M.; Delogu, F.; Dutkova, E.; Gaffet, E.; Gotor, F. J.; Kumar, R.; Mitov, I.; Rojac, T.; Senna, M.; Streletskii, A.; Wieczorek-Ciurowa, K., Hallmarks of mechanochemistry: from nanoparticles to technology. Chem. Soc. Rev. 2013, 42, 7571-7637; (b) Tsuzuki, T.; McCormick, P. G., Mechanochemical synthesis of nanoparticles. J. Mater. Sci. 2004, 39, 5143-5146.

5. (a) Michelin, R. A.; Zanotto, L.; Braga, D.; Sabatino, P.; Angelici, R. J., Transitionmetal-promoted cyclization reactions of isocyanide ligands. Synthesis of cyclic diaminocarbenes from isocyanide complexes of palladium(II) and platinum(II) and x-ray structure of cis$\mathrm{Br} 2 \mathrm{Pt}[\mathrm{CN}(\mathrm{C} 6 \mathrm{H} 4-\mathrm{p}-\mathrm{Me}) \mathrm{CH} 2 \mathrm{CH} 2 \mathrm{~N}(\mathrm{H})](\mathrm{PPh} 3)$. Inorg. Chem. 1988, 27, 93-99; (b) Juribašić, M.; Užarević, K.; Gracin, D.; Ćurić, M., Mechanochemical C-H bond activation: rapid and regioselective double cyclopalladation monitored by in situ Raman spectroscopy. Chem. Commun. 2014, 50, 10287-10290; (c) Do, J.-L.; Mottillo, C.; Tan, D.; Štrukil, V.; Friščić, T., Mechanochemical Ruthenium-Catalyzed Olefin Metathesis. J. Am. Chem. Soc. 2015, 137, 24762479; (d) Hermann, G. N.; Becker, P.; Bolm, C., Mechanochemical Rhodium(III)-Catalyzed C-H Bond Functionalization of Acetanilides under Solventless Conditions in a Ball Mill. Angew. Chem. Int. Ed. 2015, 54, 7414-7417; (e) Yepez, A.; Hidalgo, J. M.; Pineda, A.; Cerny, R.; Jisa, P.; Garcia, A.; Romero, A. A.; Luque, R., Mechanistic insights into the hydroconversion of cinnamaldehyde using mechanochemically-synthesized Pd/Al-SBA-15 catalysts. Green Chem. 2015, 17, 565-572; (f) Allenbaugh, R. J.; Zachary, J. R., Kinetic analysis of the mechanochemical syntheses of dialkyl 2,2'-bipyridyl-4,4'-dicarboxylate complexes of palladium. Liq. Cryst. 2016, Ahead of Print; (g) Chen, L.; Regan, M.; Mack, J., The Choice Is Yours: Using Liquid-Assisted Grinding To Choose between Products in the Palladium-Catalyzed Dimerization of Terminal Alkynes. ACS Catalysis 2016, 6, 868-872; (h) Hermann, G. N.; Becker, P.; Bolm, C., Mechanochemical Iridium(III)-Catalyzed C-H Bond Amidation of Benzamides with Sulfonyl Azides under Solvent-Free Conditions in a Ball Mill. Angew. Chem. Int. Ed. 2016, 55, 3781-3784; (i) Lou, S.-J.; Mao, Y.-J.; Xu, D.-Q.; He, J.-Q.; Chen, Q.; Xu, Z.-Y., Fast and 
Selective Dehydrogenative C-H/C-H Arylation Using Mechanochemistry. ACS Catalysis 2016, 3890-3894; (j) Xu, C.; De, S.; Balu, A. M.; Ojeda, M.; Luque, R., Mechanochemical synthesis of advanced nanomaterials for catalytic applications. Chem. Commun. 2015, 51, 6698-6713.

6. (a) Garay, A. L.; Pichon, A.; James, S. L., Solvent-free synthesis of metal complex. Chem. Soc. Rev. 2007, 36, 846-855; (b) Bowmaker, G. A.; Chaichit, N.; Pakawatchai, C.; Skelton, B. W.; White, A. H., Solvent-assisted mechanochemical synthesis of metal complexes. Dalton Trans. 2008, 2926-2928; (c) Kuroda, R.; Yoshida, J.; Nakamura, A.; Nishikiori, S.-i., Annealing assisted mechanochemical syntheses of transition-metal coordination compounds and co-crystal formation. CrystEngComm 2009, 11, 427-432; (d) Friščić, T.; Halasz, I.; Štrukil, V.; Eckert-Maksić, M.; Dinnebier, R. E., Clean and efficient synthesis using mechanochemistry: coordination polymers, metal-organic frameworks and metallodrugs. Croat. Chem. Acta 2012, 85, 367-378; (e) Friščić, T., Ball-milling mechanochemical synthesis of coordination bonds: discrete units, polymers and porous materials. RSC Green Chem. Ser. 2015, 31, 151-189; (f) Mottillo, C.; Friščić, T., Advances in Solid-State Transformations of Coordination Bonds: From the Ball Mill to the Aging Chamber. Molecules 2017, 22.

7. (a) Trask, A. V.; van de Streek, J.; Motherwell, W. D. S.; Jones, W., Achieving Polymorphic and Stoichiometric Diversity in Cocrystal Formation: Importance of Solid-State Grinding, Powder X-ray Structure Determination, and Seeding. Cryst. Growth Des. 2005, 5 , 2233-2241; (b) Štrukil, V.; Margetić, D.; Igrc, M. D.; Eckert-Maksić, M.; Friščić, T., Desymmetrisation of aromatic diamines and synthesis of non-symmetrical thiourea derivatives by click-mechanochemistry. Chem. Commun. 2012, 48, 9705-9707; (c) Schmidt, R.; Stolle, A.; Ondruschka, B., Aromatic substitution in ball mills: formation of aryl chlorides and bromides using potassium peroxomonosulfate and NaX. Green Chem. 2012, 14, 1673-1679.

8. (a) Katsenis, A. D.; Puškarić, A.; Štrukil, V.; Mottillo, C.; Julien, P. A.; Užarević, K.; Pham, M.-H. H.; Do, T.-O. O.; Kimber, S. A.; Lazić, P.; Magdysyuk, O.; Dinnebier, R. E.; Halasz, I.; Friščić, T., In situ X-ray diffraction monitoring of a mechanochemical reaction reveals a unique topology metal-organic framework. Nat. Commun. 2015, 6, 6662; (b) Štrukil, V.; Gracin, D.; Magdysyuk, O. V.; Dinnebier, R. E.; Friščić, T., Trapping Reactive Intermediates by Mechanochemistry: Elusive Aryl N-Thiocarbamoylbenzotriazoles as Bench-Stable Reagents. Angew. Chem. Int. Ed. 2015; (c) Rightmire, N. R.; Hanusa, T. P.; Rheingold, A. L., Mechanochemical Synthesis of [1,3-(SiMe3)2C3H3]3(A1,Sc), a Base-Free Tris(allyl)aluminum Complex and Its Scandium Analogue. Organometallics 2014, 33, 5952-5955; (d) Shi, Y. X.; Xu, K.; Clegg, J. K.; Ganguly, R.; Hirao, H.; Friščić, T.; García, F., The First Synthesis of the Sterically Encumbered Adamantoid Phosphazane P4(NtBu)6: Enabled by Mechanochemistry. Angew. Chem. Int. Ed. 2016, 55, 12736-12740.

9. $\quad$ Friščić, T., Metal-Organic Frameworks: Mechanochemical Synthesis Strategies. In Encyclopedia of Inorganic and Bioinorganic Chemistry, John Wiley \& Sons, Ltd: 2011.

10. (a) Biswal, B. P.; Chandra, S.; Kandambeth, S.; Lukose, B.; Heine, T.; Banerjee, R., Mechanochemical Synthesis of Chemically Stable Isoreticular Covalent Organic Frameworks. $J$. Am. Chem. Soc. 2013, 135, 5328-5331; (b) Chandra, S.; Kandambeth, S.; Biswal, B. P.; Lukose, B.; Kunjir, S. M.; Chaudhary, M.; Babarao, R.; Heine, T.; Banerjee, R., Chemically Stable Multilayered Covalent Organic Nanosheets from Covalent Organic Frameworks via Mechanical Delamination. J. Am. Chem. Soc. 2013, 135, 17853-17861.

11. Pichon, A.; Lazuen-Garay, A.; James, S. L., Solvent-free synthesis of a microporous metal-organic framework. CrystEngComm 2006, 8, 211-214. 
12. (a) Pichon, A.; James, S. L., An array-based study of reactivity under solvent -free mechanochemical conditions-insights and trends. CrystEngComm 2008, 10, 1839-1847; (b) Friščić, T.; Fábián, L., Mechanochemical conversion of a metal oxide into coordination polymers and porous frameworks using liquid-assisted grinding (LAG). CrystEngComm 2009, 11, 743745; (c) Beldon, P. J.; Fábián, L.; Stein, R. S.; Thirumurugan, A.; Cheetham, A. K.; Friščić, T., Rapid room-temperature synthesis of zeolitic imidazolate frameworks by using mechanochemistry. Angew. Chem. Int. Ed. 2010, 49, 9640-9643; (d) Yuan, W.; Friščić, T.; Apperley, D.; James, S. L., High Reactivity of Metal-Organic Frameworks under Grinding Conditions: Parallels with Organic Molecular Materials. Angew. Chem. Int. Ed. 2010, 49, 39163919; (e) Yuan, W.; O'Connor, J.; James*, S. L., Mechanochemical synthesis of homo- and hetero-rare-earth(III) metal-organic frameworks by ball milling. CrystEngComm 2010, 12. 13. Prochowicz, D.; Sokolowski, K.; Justyniak, I.; Kornowicz, A.; Fairen-Jimenez, D.; Friščić, T.; Lewinski, J., A mechanochemical strategy for IRMOF assembly based on predesigned oxo-zinc precursors. Chem. Commun. 2015, 51, 4032-4035.

14. Pilloni, M.; Padella, F.; Ennas, G.; Lai, S.; Bellusci, M.; Rombi, E.; Sini, F.; Pentimalli, M.; Delitala, C.; Scano, A.; Cabras, V.; Ferino, I., Liquid-assisted mechanochemical synthesis of an iron carboxylate Metal Organic Framework and its evaluation in diesel fuel desulfurization. Microporous Mesoporous Mat. 2015, 213, 14-21.

15. Julien, P. A.; Užarević, K.; Katsenis, A. D.; Kimber, S. A. J.; Wang, T.; Farha, O. K.; Zhang, Y.; Casaban, J.; Germann, L. S.; Etter, M.; Dinnebier, R. E.; James, S. L.; Halasz, I.; Friščić, T., In Situ Monitoring and Mechanism of the Mechanochemical Formation of a Microporous MOF-74 Framework. J. Am. Chem. Soc. 2016, 138, 2929-2932.

16. Užarević, K.; Wang, T. C.; Moon, S.-Y.; Fidelli, A. M.; Hupp, J. T.; Farha, O. K.; Friščić, T., Mechanochemical and solvent-free assembly of zirconium-based metal-organic frameworks. Chem. Commun. 2016, 52, 2133-2136.

17. (a) Crawford, D.; Casaban, J.; Haydon, R.; Giri, N.; McNally, T.; James, S. L., Synthesis by extrusion: continuous, large-scale preparation of MOFs using little or no solvent. Chem. Sci. 2015, 6, 1645-1649; (b) Feng, X.; Jia, C.; Wang, J.; Cao, X.; Tang, P.; Yuan, W., Efficient vapor-assisted aging synthesis of functional and highly crystalline $\mathrm{MOF}$ from $\mathrm{CuO}$ and rare earth sesquioxides/carbonates. Green Chem. 2015, 17, 3740-3745; (c) Friščić, T.; Reid, D.; Halasz, I.; Stein, R.; Dinnebier, R.; Duer, M., Ion- and liquid-assisted grinding: improved mechanochemical synthesis of metal-organic frameworks reveals salt inclusion and anion templating. Angew. Chem. Int. Ed. 2010, 49, 712-715.

18. Chui, S. S.-Y.; Lo, S. M.-F.; Charmant, J. P. H.; Orpen, G.; Williams, I. D., A Chemically Functionalizable Nanoporous Material [Cu3(TMA)2(H2O)3]n. Science 1999, 283, $1148-1150$.

19. (a) Friščić, T.; Fabian, L.; Burley, J. C.; Jones, W.; Motherwell, W. D. S., Exploring cocrystal-cocrystal reactivity via liquid-assisted grinding: the assembling of racemic and dismantling of enantiomeric cocrystals. Chem. Commun. 2006, 5009-5011; (b) Friščić, T.; Trask, A. V.; Jones, W.; Motherwell, W. D. S., Screening for Inclusion Compounds and Systematic Construction of Three-Component Solids by Liquid-Assisted Grinding. Angew. Chem. Int. Ed. 2006, $45,7546-7550$.

20. $\quad$ (a) Klimakow, M.; Klobes, P.; Thünemann, A. F.; Rademann, K.; Emmerling, F., Mechanochemical Synthesis of Metal-Organic Frameworks: A Fast and Facile Approach toward Quantitative Yields and High Specific Surface Areas. Chem. Mater. 2010, 22, 5216-5221; (b) Yuan, W.; Garay, A.; Pichon, A.; Clowes, R.; Wood, C. D.; Cooper, A. I.; James, S. L., Study of 
the mechanochemical formation and resulting properties of an archetypal MOF: Cu3(BTC)2 (BTC = 1,3,5-benzenetricarboxylate ). CrystEngComm 2010, 12, 4063-4065.

21. Tireli, M.; Juribašić Kulcsar, M.; Cindro, N.; Gracin, D.; Biliškov, N.; Borovina, M.; Ćurić, M.; Halasz, I.; Užarević, K., Mechanochemical reactions studied by in situ Raman spectroscopy: base catalysis in liquid-assisted grinding. Chem. Commun. 2015, 51, 8058-8061. 22. (a) Bordiga, S.; Regli, L.; Bonino, F.; Groppo, E.; Lamberti, C.; Xiao, B.; Wheatley, P. S.; Morris, R. E.; Zecchina, A., Adsorption properties of HKUST-1 toward hydrogen and other small molecules monitored by IR. Phys. Chem. Chem. Phys. 2007, 9, 2676-2685; (b) Nuzhdin, A. L.; Shalygin, A. S.; Artiukha, E. A.; Chibiryaev, A. M.; Bukhtiyarova, G. A.; Martyanov, O. N., HKUST-1 silica aerogel composites: novel materials for the separation of saturated and unsaturated hydrocarbons by conventional liquid chromatography. $R S C A d v$. 2016, 6, 6250162507; (c) Peralta, D.; Barthelet, K.; Pérez-Pellitero, J.; Chizallet, C.; Chaplais, G.; SimonMasseron, A.; Pirngruber, G. D., Adsorption and Separation of Xylene Isomers: CPO-27-Ni vs HKUST-1 vs NaY. J. Phys. Chem. C 2012, 116, 21844-21855.

23. (a) Sachse, A.; Ameloot, R.; Coq, B.; Fajula, F.; Coasne, B.; De Vos, D.; Galarneau, A., In situ synthesis of Cu-BTC (HKUST-1) in macro-/mesoporous silica monoliths for continuous flow catalysis. Chem. Commun. 2012, 48, 4749-4751; (b) Lee, J.; Farha, O. K.; Roberts, J.; Scheidt, K. A.; Nguyen, S. T.; Hupp, J. T., Metal-organic framework materials as catalysts. Chem. Soc. Rev. 2009, 38, 1450-1459; (c) Schlichte, K.; Kratzke, T.; Kaskel, S., Improved synthesis, thermal stability and catalytic properties of the metal-organic framework compound Cu3(BTC)2. Microporous Mesoporous Mater. 2004, 73, 81-88.

24. Dhakshinamoorthy, A.; Alvaro, M.; Garcia, H., Commercial metal-organic frameworks as heterogeneous catalysts. Chem. Commun. 2012, 48, 11275-11288.

25. Friščić, T.; Halasz, I.; Beldon, P.; Belenguer, A.; Adams, F.; Kimber, S.; Honkimäki, V.; Dinnebier, R., Real-time and in situ monitoring of mechanochemical milling reactions. Nat.

Chem. 2013, 5, 66-73.

26. Friščić, T.; Childs, S. L.; Rizvi, S. A. A.; Jones, W., The role of solvent in mechanochemical and sonochemical cocrystal formation: a solubility-based approach for predicting cocrystallisation outcome. CrystEngComm 2009, 11, 418-426.

27. Halasz, I.; Kimber, S. A.; Beldon, P. J.; Belenguer, A. M.; Adams, F.; Honkimäki, V.; Nightingale, R. C.; Dinnebier, R. E.; Friščić, T., In situ and real-time monitoring of mechanochemical milling reactions using synchrotron X-ray diffraction. Nat. Protoc. 2013, 8 , 1718-1729.

28. Paris, O.; Li, C.; Siegel, S.; Weseloh, G.; Emmerling, F.; Riesemeier, H.; Erko, A.; Fratzl, P., A new experimental station for simultaneous X-ray microbeam scanning for smalland wide-angle scattering and fluorescence at BESSY II. J. Appl. Crystallogr. 2007, 40, s466s470.

29. Pawley, G., Unit-cell refinement from powder diffraction scans. J. Appl. Crystallogr. 1981, 14, 357-361.

30. TOPAS version 4.2, Bruker-AXS: Karlsruhe, Germany.

31. Mathematica, Version 9.0, Wolfram Research, Inc.: Champaign, Illinois, 2012.

32. Sonneveld, E. J.; Visser, J. W., Automatic collection of powder data from photographs. J. Appl. Crystallogr. 1975, 8, 1-7.

33. Hinrichsen, B.; Dinnebier, R. E.; Jansen, M., Powder3D: An easy to use program for data reduction and graphical presentation of large numbers of powder diffraction patterns. $Z$.

Kristallogr. 2006, 23 (Suppl), 231-236. 
34. Altomare, A.; Cuocci, C.; Giacovazzo, C.; Moliterni, A.; Rizzi, R.; Corriero, N.; Falcicchio, A., EXPO2013: a kit of tools for phasing crystal structures from powder data. $J$. Appl. Crystallogr. 2013, 46, 1231-1235.

35. (a) Užarević, K.; Halasz, I.; Đilović, I.; Bregović, N.; Rubčić, M.; Matković-Čalogović, D.; Tomišić, V., Dynamic molecular recognition in solid state for separating mixtures of isomeric dicarboxylic acids. Angew. Chem. Int. Ed. 2013, 52, 5504-5508; (b) Gracin, D.; Štrukil, V.; Friščić, T.; Halasz, I.; Užarević, K., Laboratory Real-Time and In Situ Monitoring of Mechanochemical Milling Reactions by Raman Spectroscopy. Angew. Chem. Int. Ed. 2014, 53, 6193-6197; (c) Trobs, L.; Emmerling, F., Mechanochemical synthesis and characterisation of cocrystals and metal organic compounds. Faraday Discuss. 2014, 170, 109-119.

36. (a) Sharrock, P.; Melník, M., Copper(II) acetates: from dimer to monomer. Can. J. Chem. 1985, 63, 52-56; (b) Gregson, A. K.; Martin, R. L.; Mitra, S., The Magnetic Anisotropy and Electronic Structure of Binuclear Copper(II) Acetate Monohydrate. Proc. R. Soc. London, A 1971, 320, 473; (c) Bleaney, B.; Bowers, K. D., Anomalous Paramagnetism of Copper Acetate. Proc. R. Soc. London, A 1952, 214, 451.

37. (a) Danilovich, I.; Merkulova, A.; Polovkova, A.; Zvereva, E.; Ovchenkov, Y.; Morozov, I.; Rahaman, B.; Saha-Dasgupta, T.; Balz, C.; Luetkens, H.; Volkova, O.; Shakin, A.; Vasiliev, A., Vehement Competition of Multiple Superexchange Interactions and Peculiar Magnetically Disordered State in Cu(OH)F. J. Phys. Soc. Jpn. 2016, 85, 024709; (b) Asai, T.; Saheki, H.; Kiriyama, R., Magnetic Studies on Basic Salts of Copper, Dicopper Arsenate Hydroxide, Dicopper Hydroxide Phosphate, and Dicopper Oxide Sulfate. Bull. Chem. Soc. Jpn. 1979, 52, 310-314.

38. Polona, U.; Andrej, Z.; Pavel, C.; Miha, Š.; Zvonko, J.; Jin Won, S.; Lászlo, F.; Hans van, T.; Louis Claude, C. B.; Denis, A., The impact of ageing on the magnetic properties of $\mathrm{Cu}(\mathrm{OH}) 2$ nanoribbons. Nanotechnology 2005, 16, 1623.

39. Vierke, G., Electron spin resonance spectra of the reaction products of copper(II) hydroxide suspensions in methanol with hydrogen peroxide and of polycrystalline copper(II) hydroxide and copper(II) peroxide. J. Chem. Soc., Faraday Trans.1 1973, 69, 1523-1531. 40. (a) Pöppl, A.; Kunz, S.; Himsl, D.; Hartmann, M., CW and Pulsed ESR Spectroscopy of Cupric Ions in the Metal-Organic Framework Compound Cu3(BTC)2. J. Phys. Chem. C 2008, 112, 2678-2684; (b) Todaro, M.; Buscarino, G.; Sciortino, L.; Alessi, A.; Messina, F.; Taddei, M.; Ranocchiari, M.; Cannas, M.; Gelardi, F. M., Decomposition Process of Carboxylate MOF HKUST-1 Unveiled at the Atomic Scale Level. J. Phys. Chem. C 2016, 120, 12879-12889. 41. Zhang, X. X.; Chui, S. S.-Y.; Williams, I. D., Cooperative magnetic behavior in the coordination polymers [Cu3(TMA)2L3](L=H2O, pyridine). J. Appl. Phys. 2000, 87, 6007-6009. 42. Garribba, E.; Micera, G., The Determination of the Geometry of $\mathrm{Cu}(\mathrm{II})$ Complexes: An EPR Spectroscopy Experiment. J. Chem. Educ. 2006, 83, 1229. 
For Table of Contents Only

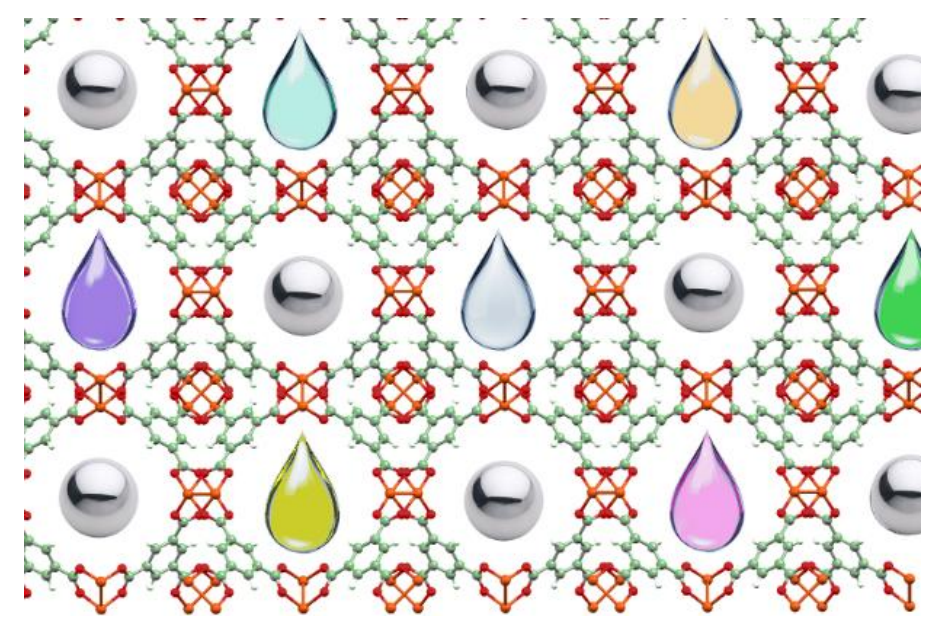

Synopsis. High-energy synchrotron powder X-ray diffraction was applied for studying the role of liquid additives on the mechanochemical synthesis of archetypal metal-organic framework HKUST-1. The in situ monitoring revealed three different reaction pathways depending on the additive used and mechanochemical reaction conditions, and also helped in isolating and characterizing two new intermediates in mechanosynthesis of this widely investigated metalorganic framework. 